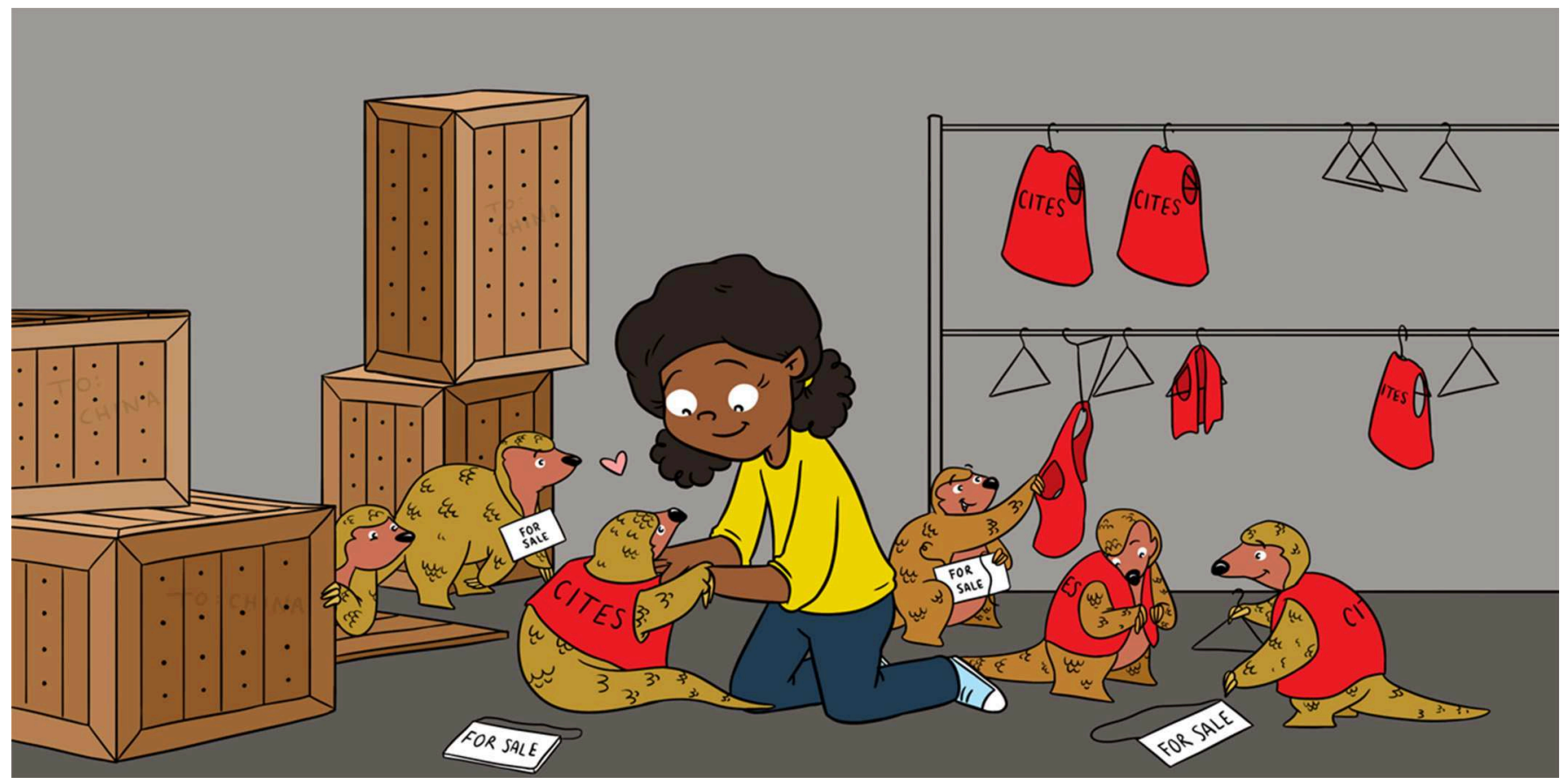

\title{
PANGOLINS IN TROUBLE
}

\section{Sarah Heinrich ${ }^{1 *}$, Joshua V. Ross ${ }^{2}$ and Phillip Cassey ${ }^{1}$}

${ }^{1}$ Invasion Science and Wildlife Ecology Group, Centre for Applied Conservation Science, School of Biological Sciences, The University of Adelaide, Adelaide, SA, Australia

${ }^{2}$ Stochastic Modelling and Operations Research Group, School of Mathematical Sciences, The University of Adelaide, Adelaide, SA, Australia

YOUNG REVIEWER:

LILU

AGE: 10
The illegal wildlife trade (also called wildlife trafficking) is of growing concern worldwide. Wildlife trafficking is threatening a large number of plant and animal species. Many people sell and buy different wildlife species (both alive and as body parts), and the survival of these species may be threatened if this trafficking continues. In this article, we will tell you the story of the pangolins, which have been called the world's most heavily trafficked wild mammals. Pangolins are the only mammals that are covered in scales. Eight species of pangolins exist, and all of them are threatened because they are trafficked in such high numbers. If current trafficking continues, these amazing animals may be lost forever.

\section{HAVE YOU EVER HEARD OF A PANGOLIN?}

Have you ever heard of a pangolin (pang-guh-lin)? Although the names sound similar, pangolins are not to be confused with penguins. Pangolins look a bit like walking pinecones, but they are actually 
Figure 1

The eight pangolin species of the world and their distributions (courtesy of the IUCN SSC Pangolin Specialist Group).

\section{TRAFFICKING}

The illegal trade in wildlife.

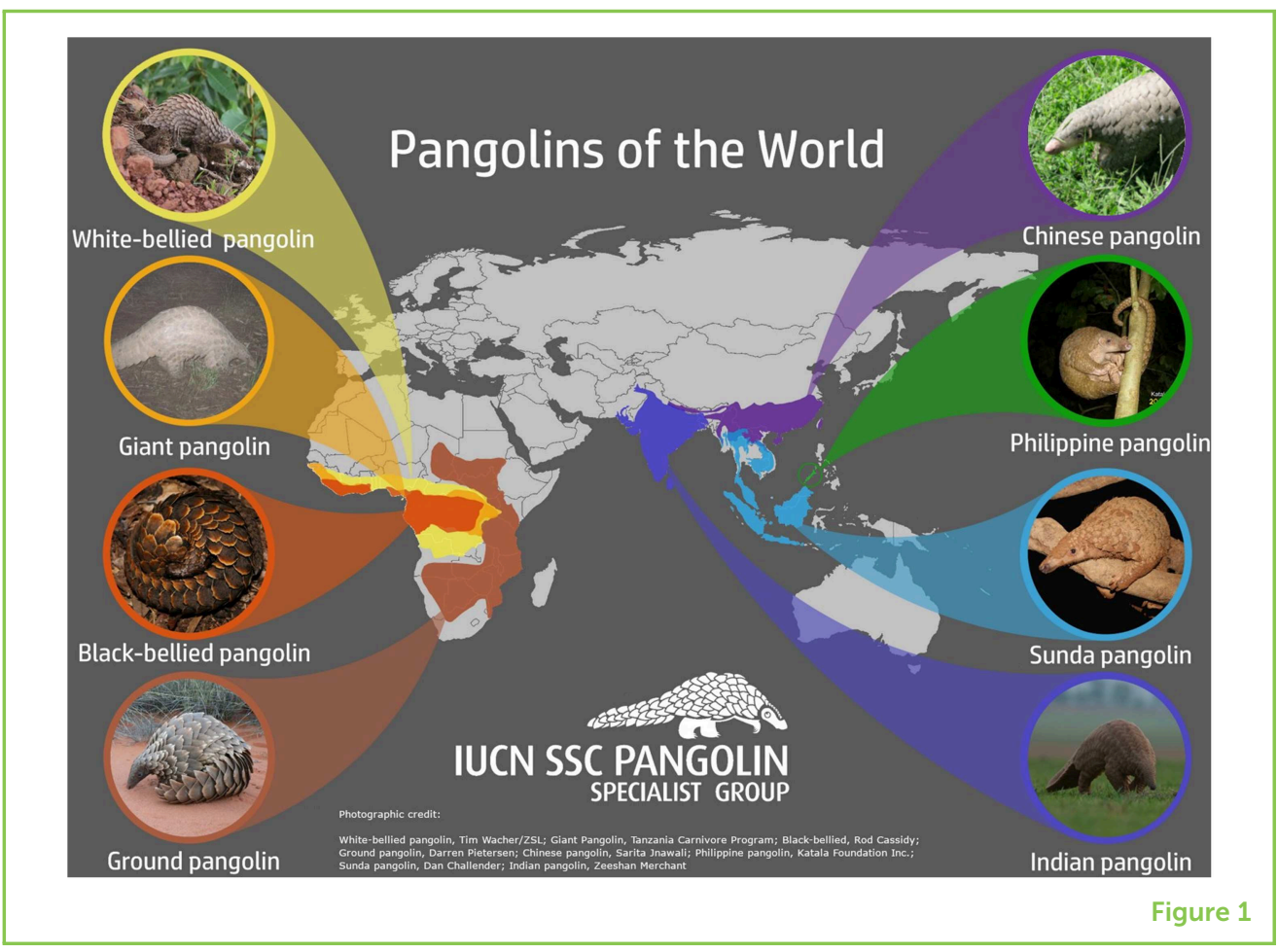

mammals. In fact, they are the only mammals that are covered in hard scales, and because their primary food source is ants, pangolins are also called scaly anteaters. There are eight species of pangolins, four of which live in Africa and four in Asia (Figure 1). Pangolins are very diverse. Some live in tropical forests, where they use their long tails to climb trees, while others walk on two legs through the vast deserts and savannahs of Africa. Pangolins are a very ancient line of mammals, and fossil evidence suggests that they have been around for over 40 million years. Recently, pangolins have become quite famous. Sadly, this happened for all the wrong reasons, and they are now known as the most heavily trafficked wild mammals in the world [1].

\section{WHAT IS WILDLIFE TRADE AND TRAFFICKING?}

Wildlife trade, which can be legal, and wildlife trafficking, which is illegal trade, includes thousands of species (and millions of individual organisms) that are traded every year. Wildlife trade is very diverse and includes species of plants, fungi, and all kinds of animals, such as reptiles, birds, mammals, amphibians, fish, and insects. There are many reasons why species are traded. The most common reasons wildlife is traded are that the traded plants and animals are used for food, medicine, pets, or to create luxury items, such as souvenirs, jewelery, clothing, or furniture. In some parts of the world, people depend on wildlife for these reasons. For species that occur in high numbers, the wild populations of animals are not usually affected too much when people use them in these ways. 
Some species of wild animals are relatively easy to breed in captivity. The offspring (meaning the babies) of these captive bred animals can then be traded. This is often the case for some furbearing animals, which are kept and bred in captivity so that their fur and pelts can be made into clothing, such as coats or hats. Sometimes, however, species only occur in lower numbers, or cannot easily be bred in captivity. This is true for pangolins. When wildlife species only occur in low numbers and cannot easily be bred in captivity, then their use by people becomes a problem and can lead to the extinction of the species.

The trafficking of wildlife is of growing concern worldwide. Wildlife trafficking occurs when people sell or buy wildlife illegally. Some species are protected by law because they are endangered and their survival in the wild is threatened. It is important to know that most endangered species are threatened not only by trade and trafficking, but also by other factors, including habitat destruction, climate change, or the introduction of invasive species that do not normally live in the area. It is believed, however, that wildlife trafficking is contributing greatly to the loss of species worldwide.

\section{AN AGREEMENT TO PROTECT SPECIES FROM INTERNATIONAL TRADE: CITES}

\section{CITES}

The Convention on International Trade in Endangered Species of Wild Fauna and Flora (CITES) is a global agreement between governments, with the aim to regulate wildlife trade in threatened species.
To control the trade in species that are threatened because of trade, a global agreement was established in 1975. The Convention on International Trade in Endangered Species of Wild Fauna and Flora, or "CITES" for short, was established to help protect wildlife species that are threatened by international trade, or species that may be threatened in the future if current levels of trade continue. It is important to know that CITES only regulates the legal international wildlife trade, but not the trade that occurs within a country. Not all wildlife species are listed in CITES, but only those that have been shown to need special protection from international trade. Examples of animals that are listed in CITES include tigers, rhinoceroses, and-you may have guessed it-pangolins.

\section{THE GLOBAL PANGOLIN TRADE}

Now, you may wonder why pangolins are traded so much. Most of the demand for pangolins comes from Asia. China is the main destination for pangolins, but pangolin trade occurs on a global scale-even Europe, Australia, and America are involved. The pangolin meat and scales are the biggest reason these animals are traded. The scales are used in traditional medicines, because some people believe that they are a remedy for a variety of illnesses. This is probably untrue, as pangolin scales are made of keratin-the same material our fingernails are made of. Pangolin meat is also consumed in restaurants, especially in Vietnam. Pangolin meat is among the most expensive meats that can be bought in Asia, and people buy this expensive food, for example, to 
Figure 2

The countries involved in pangolin trafficking from 2010 to 2015 . based on the number of trafficking incidents per country (indicated by the color-coded areas listed in the key), and pangolin trafficking routes between continents (amended from Heinrich et al. [4]). The arrows represent trafficking routes (the thicker the lines, the more trafficking occurred). Circular arrows represent trafficking within a continent (for example, North America, Africa, Europe, Asia).

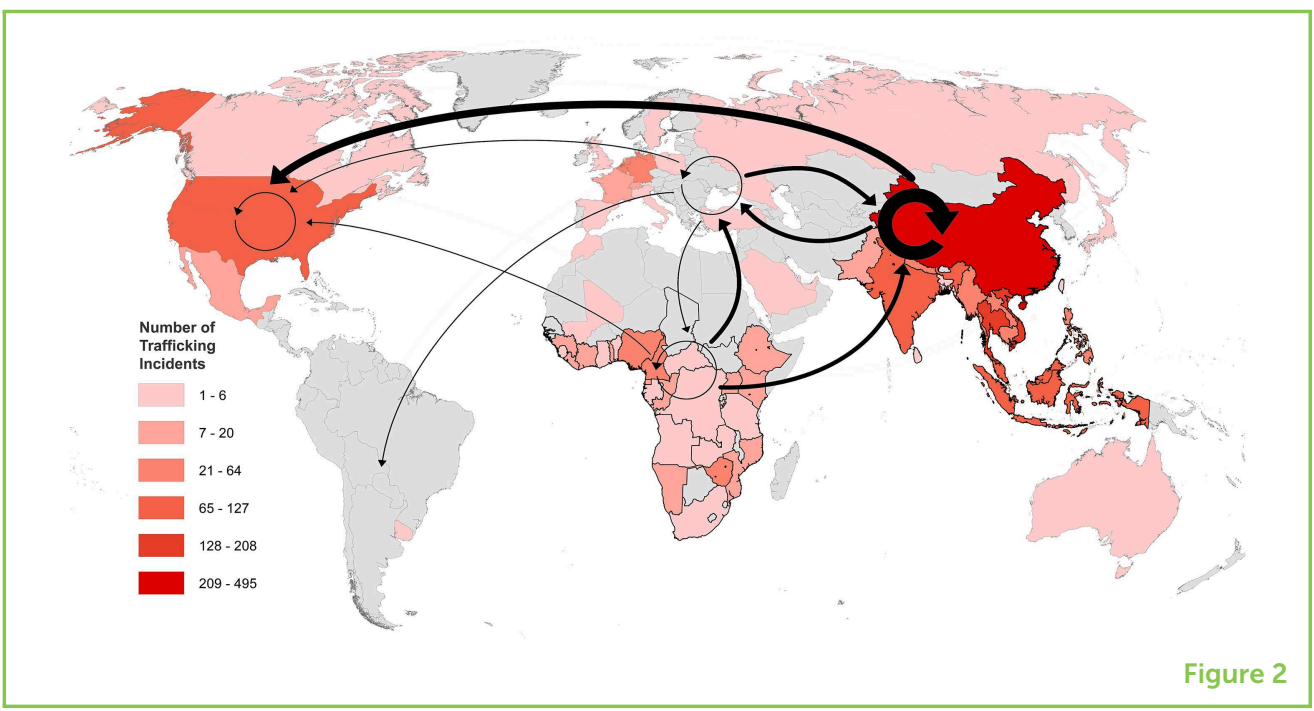

impress their friends or business partners. Other parts of the pangolin body are also used, such as the organs (for medicine again), or the skin. The skin is used to make luxury leather items, such as cowboy boots, belts, or wallets. In the past, most of these luxury items were sold in the United States of America, but this is illegal today.

For a long time, it was legal to trade pangolins in many countries. The use and trade of pangolins date back centuries. It has only been recognized quite recently that pangolins were being traded and trafficked in such large numbers that they required special protection to protect them from extinction. In the year 2000, a ban was established that made it illegal to trade any of the Asian pangolin species internationally for commercial purposes (which means that they could not be sold anymore). This ban had two consequences. First, the trade switched from the Asian pangolin species to the African species. The trade in African pangolin species was regulated at the time, but they were still allowed to be traded internationally. To add to the pressure on the species, the African pangolins were now not only traded within Africa but were also increasingly shipped to Asia [2]. Second, the establishment of the trade ban for Asian pangolin species has not stopped the trade but has made it illegal (Figure 2). When trade of Asian pangolins became illegal, people still wanted to eat and use pangolins, so the pangolins were increasingly hunted and sold illegally [3]. This had very negative effects on pangolin populations, which had been in decline already before the international trade ban in 2000. It is estimated that more than a million pangolins were trafficked, from 2000 to 2013, which ultimately gave pangolins the sad title of the most heavily trafficked wild mammal in the world.

\section{THE FUTURE OF PANGOLINS IS IN OUR HANDS}

Only 2 years ago, in January 2017, all eight pangolin species were fully protected by CITES. This finally provided pangolins with the protection 


\section{TRAFFICKERS}

The people that are involved in illegal wildlife trade and who move the illegal wildlife products from one place to another.

\section{SEIZURE}

The interception and confiscation of illegally traded wildlife products by law enforcement officials, such as police or customs. they needed, at least in theory. As with the trade ban established in 2000 for the Asian species, things have not quite work out as planned. The trafficking of pangolins continues to this day. Currently, scientists are trying to estimate the true number of pangolins in the wild. It is a bit of a mystery how traffickers, the people who are involved in the illegal trade, still find so many pangolins. In two recent seizures (when the police or customs intercept and confiscate shipments of illegal products), almost 26 tons of pangolin scales were found. That means $\sim 50,000$ pangolins had to die for those two shipments! Most of the big shipments nowadays appear to be coming from Africa, and some of them are intercepted en route between Africa and Asia. However, there is much more trafficking going on than we know about. The traffickers operate illegally, and we can therefore only estimate how many pangolins are trafficked based on what is seized by police and customs. Many traffickers are very smart and they often do not get caught when they are trafficking pangolins. That is a big problem that puts the survival of pangolins at risk.

At the moment, the future looks very gloomy for pangolins, but there is still hope! Now that you know about the trouble that pangolins are in, you can help by spreading the word about them. The more people know about pangolins, the better! If we can raise awareness and get people to change their attitudes toward eating and using wildlife, pangolins may still be able to recover. Given the long history of pangolin trade and trafficking, it is surprising that these amazing animals are still around. Yet, here they are, surprisingly resilient and they may just need a little more help from us in the coming years. There are many things that need to be improved to help pangolins. These include better law enforcement efforts in many countries, advertisement campaigns to reduce demand in countries where pangolins are consumed, better protection for pangolins in the countries they live in, and providing alternative jobs for the people who rely on hunting wildlife. All of these things will need to be addressed very soon, but it can be done. The future of pangolins, and many other species that are severely threatened by wildlife trafficking, is ultimately in our hands.

\section{ACKNOWLEDGMENTS}

We would like to thank Madeleine Ross and Eric Cassey for providing useful comments on an earlier draft of the manuscript. Many thanks as well to the young reviewers and scientific advisers for reviewing the manuscript and providing useful feedback. We would also like to thank Dr. Dan Challender for giving us permission to use Figure 1.

\section{REFERENCES}

1. Challender, D. W. S., Waterman, C., and Baillie, J. 2014. Scaling Up Pangolin Conservation. IUCN SSC Pangolin Specialist Group Conservation Action Plan. London: Zoological Society of London. 
2. Heinrich, S., Wittmann, T. A., Prowse, T. A., Ross, J. V., Delean, S., Shepherd, C. R., et al. 2016. Where did all the pangolins go? International CITES trade in pangolin species. Glob. Ecol. Conserv. 8:241-53. doi: 10.1016/j.gecco.2016.09.007

3. Challender, D. W. S., Harrop, S. R., and MacMillan, D. C. 2015. Understanding markets to conserve trade-threatened species in CITES. Biol. Conserv. 187:249-59. doi: 10.1016/j.biocon.2015.04.015

4. Heinrich, S., Wittmann, T. A., Ross, J. V., Shepherd, C., Challender, D. W. S., and Cassey, P. 2017. The Global Trafficking of Pangolins: A Comprehensive Summary of Seizures and Trafficking Routes From 2010-2015. Petaling Jaya: TRAFFIC, Southeast Asia Regional Office.

SUBMITTED: 05 June 2019; ACCEPTED: 09 August 2019;

PUBLISHED ONLINE: 11 September 2019.

EDITED BY: Michele A. Johnson, Trinity University, United States

CITATION: Heinrich S, Ross JV and Cassey P (2019) Pangolins in Trouble. Front. Young Minds 7:107. doi: 10.3389/frym.2019.00107

CONFLICT OF INTEREST STATEMENT: The authors declare that the research was conducted in the absence of any commercial or financial relationships that could be construed as a potential conflict of interest.

COPYRIGHT ( 2019 Heinrich, Ross and Cassey. This is an open-access article distributed under the terms of the Creative Commons Attribution License (CC BY). The use, distribution or reproduction in other forums is permitted, provided the original author(s) and the copyright owner(s) are credited and that the original publication in this journal is cited, in accordance with accepted academic practice. No use, distribution or reproduction is permitted which does not comply with these terms.

\section{YOUNG REVIEWER}

\section{LILU, AGE: 10}

I love polar bears and I am fighting against Climate Change to save them! I love guinea pigs too.

\section{AUTHORS}

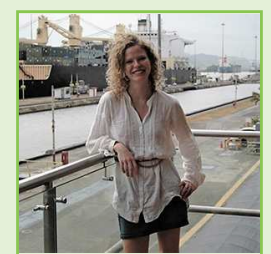

\section{SARAH HEINRICH}

Sarah Heinrich is a Ph.D. student at the University of Adelaide in Australia. She studies the international pangolin trade and is an active member of the Pangolin Specialist Group of the International Union for Conservation of Nature Species Survival Commission. Sarah is very passionate about wildlife and nature conservation. She enjoys exploring the great outdoors, watching animals in the wild and spending time with her pets. *sarah.heinrich@adelaide.edu.au 


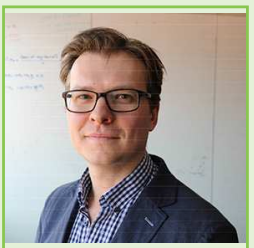

\section{JOSHUA V. ROSS}

Joshua V. Ross is an Applied Mathematician and Statistician. He develops new methods and uses these and existing tools from the mathematical sciences to understand complex systems, primarily those arising in the biological and health sciences. He enjoys spending time with his family, watching movies, and drinking coffee.

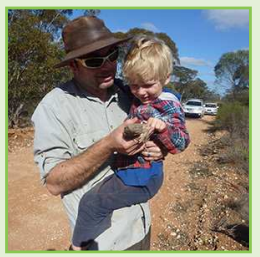

\section{PHILLIP CASSEY}

Phill Cassey is a conservation biologist who studies invasive species and the wildlife trade. He grew up in New Zealand with a passion for the land and sea-and all its wildlife. His mother was a Mathematician who taught him the value of scientific experiments, through observation and curiosity. He enjoys cooking and spending time outdoors with his family. 